\title{
Data management in drip irrigation monitoring for vineyards in pot by weighing lysimeter
}

\author{
A. Ruiz Canales ${ }^{1}$, A. Jaén Ruiz ${ }^{1}$, L. Ruiz Peñalver ${ }^{2}$, H. Puerto \\ Molina $^{1}$, D. Intrigliolo Molina ${ }^{3}$ \& J. M. Molina Martínez ${ }^{2}$ \\ ${ }^{1}$ Water and Energy for a Sustainable Agriculture, \\ High Polytechnic School of Orihuela, \\ Miguel Hernandez University of Elche, Spain \\ ${ }^{2}$ Research Group in Agromotic Engineering and the Sea, \\ Polytechnic University of Cargatena, Spain \\ ${ }^{3}$ Sustainable Agriculture Center (CEDAS), \\ Valencian Institute of Agricultural Research, Moncada (Valencia), Spain
}

\begin{abstract}
In order to carry out an optimal daily irrigation scheduling for a grapevine in a pot under drip irrigation by lysimeter, a great amount of data have to be treated. The majority of data are about monitored weight variations. The rest of the data are about some climatic variables (reference evapotranspiration ETo and rainfall). This daily irrigation programming is traditionally based on physicalmathematical models (soil water balance, radiation or drainage among others). This is a Model-Driven methodology. In this paper, several Model-Driven methodologies for data management are compared and the appropriate methodology is proposed. The experiment was developed in an experimental vineyard located in Orihuela (SE Spain). For this purpose, a lysimeter designed for crops in a pot with three cell charges and a datalogger was installed. Representative data of a vineyard variety (Bobal in 110R) were collected for three months during 2012. In the experiment, drip irrigation of a grapevine in a pot was monitored. Data about weight variations of the crop and irrigation water management were collected. These data were subsequently analysed by statistical techniques that are oriented to determine the adequate data treatment. This methodology will be used in the development of applied algorithms in software for decision tools in irrigation programming for vineyard production. Keywords: irrigation, vineyard, lysimeter, data management, monitoring.
\end{abstract}




\section{Introduction}

Wine production is one of the main agricultural economic activities in the inner areas of the Valencian Community (SE Spain) as in other Mediterranean regions [1]. Nowadays, traditional vineyard varieties have been integrated in new climatic areas. Specifically, Bobal variety, is a traditional vineyard variety that is being adapted to new areas. For this purpose, a water balance experiment of a grapevine in pot (Vitis Vinifera L. cv Bobal in 110-R) under drip irrigation is proposed by weighing lysimeter. Due to the specific climatology, irrigation is required in order to obtain an adequate yield.

Soil water availability is a critical factor for wine performance and wine composition. In plots for commercial activity, this availability is monitored by the use of soil moisture gauges. The use of soil-based water status indicators have been adopted as an adequate strategy for water balance estimation and many methodologies to measure water fluxes from vineyard have been traditionally developed [2]. The ultimate objective of these techniques is to provide vine growers with information about the most appropriate volumes of irrigation to apply in each phenological period, depending on the desired yield levels and wine styles.

The use of weighing lysimeters for determining the water volumes that a crop needs is one of the most accurate methods for this purpose. There exists plenty of bibliography about the use of lysimeters for measuring the water fluxes in vineyards [3-8]. For this reason, some of the experimental data has been obtained from weighing lysimeter. Data are obtained from a datalogger that is installed in a lysimeter. The quantity of data (obtained with a frequency of 1 minute) implies that they have to be processed with some statistical treatment in order to check the data. In this paper, three types of moving average models (simple moving average, cumulative moving average and weighted moving average) are compared. A moving average model is commonly used with time series data to smooth out short-term fluctuations and highlight longer-term trends or cycles. The threshold between short-term and long-term depends on the application, and the parameters of the moving average will be set accordingly.

An added structural problem of this area is the aridity of the climate and the scarcity of water resources, which is a historical and recurring characteristic in southern Europe, where during several periods in the year, water supply is not guaranteed. In order to optimize water supply and to rationalize the management of demand of vineyards an adequate irrigation scheduling could be established.

In this communication, the study of the bases for determining the evapotranspiration of a grapevine in pot with specific conditions of irrigation and climate are established. For this purpose, a weighing lysimeter was used.

Additionally, three moving average models for data management are compared and the adequate methodology is proposed. 


\section{Material and methods}

Irrigation scheduling is basically a method for calculating how much and when irrigation water has to be applied. In order to answer these questions, some data have to be collected, which are mainly soil-based, plant-based and meteorological-based. These data are processed in the water balance. Water balance is obtained by applying a mass conservation equation [9-12]:

$$
\mathrm{ET}=\mathrm{P}+\mathrm{I} \pm \Delta \mathrm{S}-\mathrm{D}-\mathrm{R}
$$

where ET is evapotranspiration (1), $\mathrm{P}$ is rainfall, I is irrigation, $\Delta \mathrm{S}$ is the variation of water stock between two irrigation dates, $\mathrm{D}$ is the drainage under the profile and $\mathrm{R}$ is the runoff $[11,12]$. ET is obtained by multiplying reference evapotranspiration (ETo) by the crop coefficient (Kc). The first factor is related to meteorological data and the second one depends on the crop. In the development of this experiment, daily meteorological data (ETo, P) were obtained from a nearby agrometeorological station. Runoff (R) was not considered in this experiment. Values of $\mathrm{I}, \Delta \mathrm{S}$ and $\mathrm{D}$ were obtained by monitoring weight variations (every minute) by the lysimeter along the three months experiment duration. Irrigation (I) was applied according to the state of the crop and was quantified by weighing lysimeter. Variation of water stock $(\Delta \mathrm{S})$ and drainage (D) was only evaluated by weighing lysimeter after every irrigation cycle.

The experiment was carried out during the season of 2012 in a grapevine (Vitis Vinifera L. cv Bobal in 110-R) in pot under drip irrigation installed in a lysimeter. This lysimeter is located in $38^{\circ} 4^{\prime} 10.17^{\prime \prime} \mathrm{N}$ Latitude and $0^{\circ} 59^{\prime}$ 6.81' 'W Longitude. This is an experimental plot of the Escuela Politécnica Superior de Orihuela (Miguel Hernández University, Spain), in Orihuela (Alicante). The altitude of the experimental plot is 19 meters over the sea level. The rectangular-shaped plot occupies an area of $396 \mathrm{~m}^{2}$ (a length of 20 meters and a width of 18 meters). The plot is equipped with a drip irrigation system and an electric power system so control electronic devices can be connected.

The lysimeter is in the middle of 94 pots with a capacity of 50 litres per pot oriented N-S. The distance between pots is 1.35 meters and the distance between rows of pots is 2.5 meters (Figure 1 ).

Drip irrigation system consists of several connected pipes supplied from the East of the experimental plot by a pumping system. Irrigation system includes an analogical meter and a digital programmer. Primary pipe system (horizontal pipe in Figure 1) has a diameter of $20 \mathrm{~mm}$ and a length of 16 meters. Secondary pipes (sloping pipes in Figure 1) have a diameter of $16 \mathrm{~mm}$ and several lengths. Every grapevine in pot was irrigated by two emitters of $4 \mathrm{l} \cdot \mathrm{h}^{-1}$.

Time Irrigation varied from 5, 15 and 30 minutes with variable doses per plant (1.7 to 28.8 litres per plant) along the experiment.

Weighing lysimeter for crop in pot was designed in the Universidad Politécnica de Cartagena, by the Research Group in Agromotic and Sea Engineering. This device consists of a metallic structure based on aluminium profiles with three pillars. Over these pillars there is a triangular-shaped 
platform. Every pot with a grapevine is located in this platform. Growth of grapevine is facilitated by the use of trellis over the pot and it is added to the lysimeter structure. Direct weighing system is simple in conception. Under the cited platform there are three commercial weighing cells. These weighing cells are extensometric gauges (Vetek 180TA). The resistance per gauge is $30 \mathrm{~kg}$.
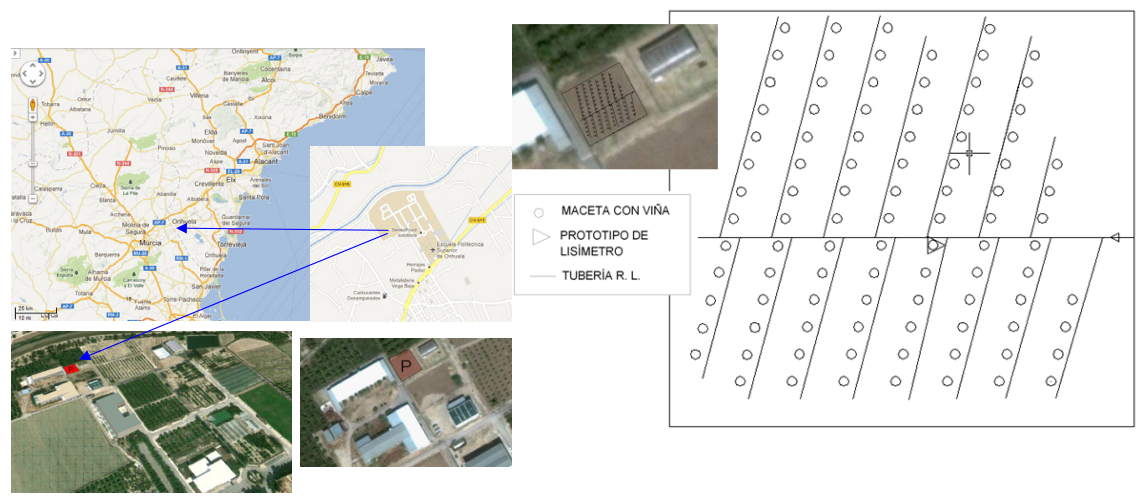

Figure 1: Location and some aerial views of the experimental plot.

To gather the data obtained by weighing cells a datalogger was installed (CR1000, Campbell Scientific). The datalogger is feed by a power source connected to the power net. Data are stored in the $4 \mathrm{MB}$ internal memory of the datalogger. Data are collected to a PC. The datalogger was programmed in order to measure data from the three weighing cells every minute and are downloaded every week.
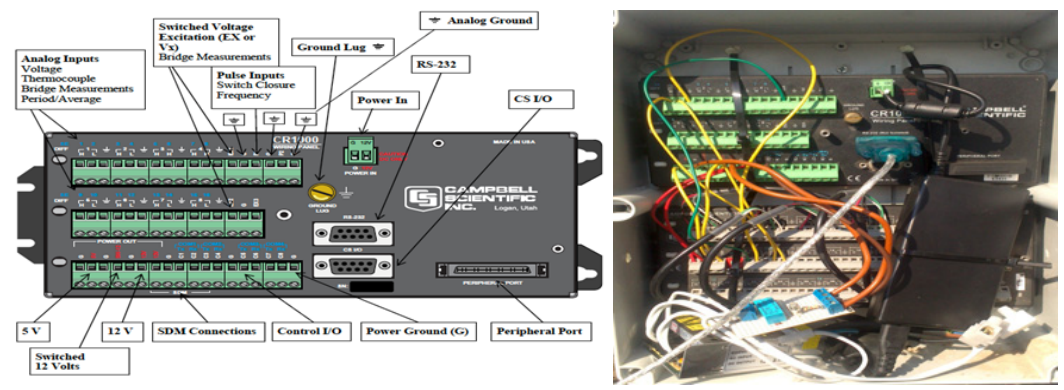

Figure 2: $\quad$ CR 1000 datalogger.

An example for determining D, I y $\Delta \mathrm{S}$ values is presented in Figure 3. Accumulated water in the soil $(\Delta S)$ is the difference between irrigation water (I) and drainage (D). Evapotranspiration (ET) is decreasing along the day until the beginning of the next cycle of irrigation (I). This cycle begins when the graphic increases quickly to reach a maximum (end of irrigation). Drainage (D) estimation depends on the irrigation cycle. When irrigation has been finalized the 
weight of the grapevine in the pot is stabilized. The minimal value during the stabilizing period is the end of the drainage (D). After the drainage, condensation is produced. This occurs before a new cycle of irrigation.

Registered values of the weight have to be processed in order to establish average values. There exist a large number of possibilities for the treatment of values. In this communication three statistical data treatment has been compared. All of them are based on moving average. Specifically, for data treatment, the three methodologies that will be used are simple moving average, cumulative moving average and weighted moving average.

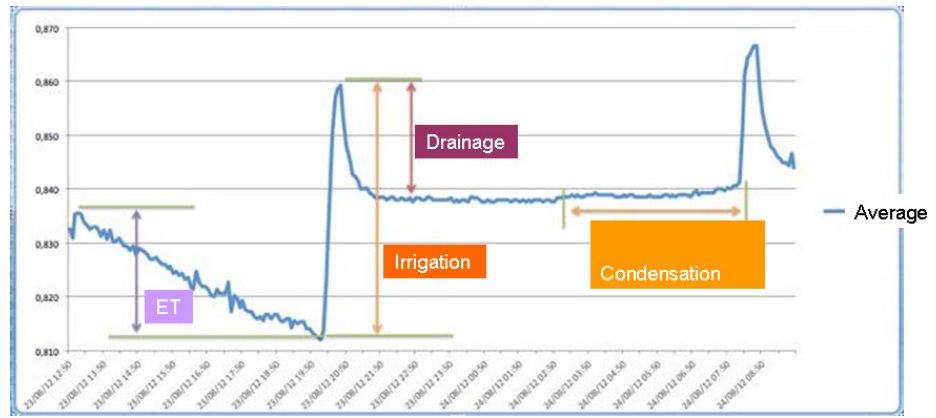

Figure 3: $\quad$ Example of measurement of drainage values (D) and accumulated water in the soil $(\Delta \mathrm{W})$ by weighing lysimeter along one day (08/23/2013-08/24/2013). Ordinates: weight registered by the lysimeter. Abscises: dates of the experiment.

In Table 1, the characteristics of moving average methodologies are presented. In financial applications a simple moving average (SMA) is the unweighted mean of the previous $n$ datum points. However, in science and engineering the mean is normally taken from an equal number of data on either side of a central value. This ensures that variations in the mean are aligned with the variations in the data rather than being shifted in time. In a cumulative moving average, the data arrive in an ordered datum stream and the statistician would like to get the average of all of the data up until the current datum point. A weighted average is any average that has multiplying factors to give different

Table 1: $\quad$ Characteristics of moving average methodologies.

\begin{tabular}{|c|c|}
\hline Methodology & Formula \\
\hline $\begin{array}{c}\text { Simple moving } \\
\text { average }\end{array}$ & $S M A=\frac{P_{M}+P_{M-1}+\ldots+P_{M-(n-1)}}{n}$ \\
\hline $\begin{array}{c}\text { Cumulative moving } \\
\text { average }\end{array}$ & $C A_{i+1}=C A_{i}+\frac{x_{i+1}-C A_{i}}{i+1}$ \\
\hline $\begin{array}{c}\text { Weighted moving } \\
\text { average }\end{array}$ & $W M A_{M}=\frac{n p_{M}+(n-1) p_{M-1}+\ldots+2 p_{(M-n+2)}+p_{(M-n+1)}}{n+(n-1)+\ldots+2+1}$ \\
\hline
\end{tabular}


weights to data at different positions in the sample window. Mathematically, the moving average is the convolution of the datum points with a fixed weighting function. One application is removing pixels from a digital graphical image.

In Table 2 the employed statistics to determine the adjustment of the data is presented. These statistical are: the mean square error (MEE), the root mean square error (RMSE) and the relative error (RE) were computed using the expressions in the table.

Table 2: $\quad$ Statistic formulas used to estimate the fit degree.

\begin{tabular}{|c|c|}
\hline Statistical & Formula \\
\hline $\begin{array}{c}\text { Mean square error } \\
\text { (MEE) }\end{array}$ & MEE $=\mathrm{N}^{-1} \Sigma \mathrm{P}_{\mathrm{i}}-\mathrm{O}_{\mathrm{i}}$ \\
\hline $\begin{array}{c}\text { Root mean square error } \\
\text { (RMSE) }\end{array}$ & $\mathrm{RMSE}=\left[\mathrm{N}^{-1} \Sigma\left(\mathrm{P}_{\mathrm{i}}-\mathrm{O}_{\mathrm{i}}\right)^{2}\right]^{1 / 2}$ \\
\hline Relative error (RE) & $\mathrm{RE}=\left(\mathrm{RMSE} / \mathrm{O}_{\text {average }}\right) * 100$ \\
\hline
\end{tabular}

\section{Results}

In this section, some results of the weighing lysimeter experiment for grapevine in pot under drip irrigation are shown. In Figure 4, some of these experimental data from the weighing lysimeter are presented.
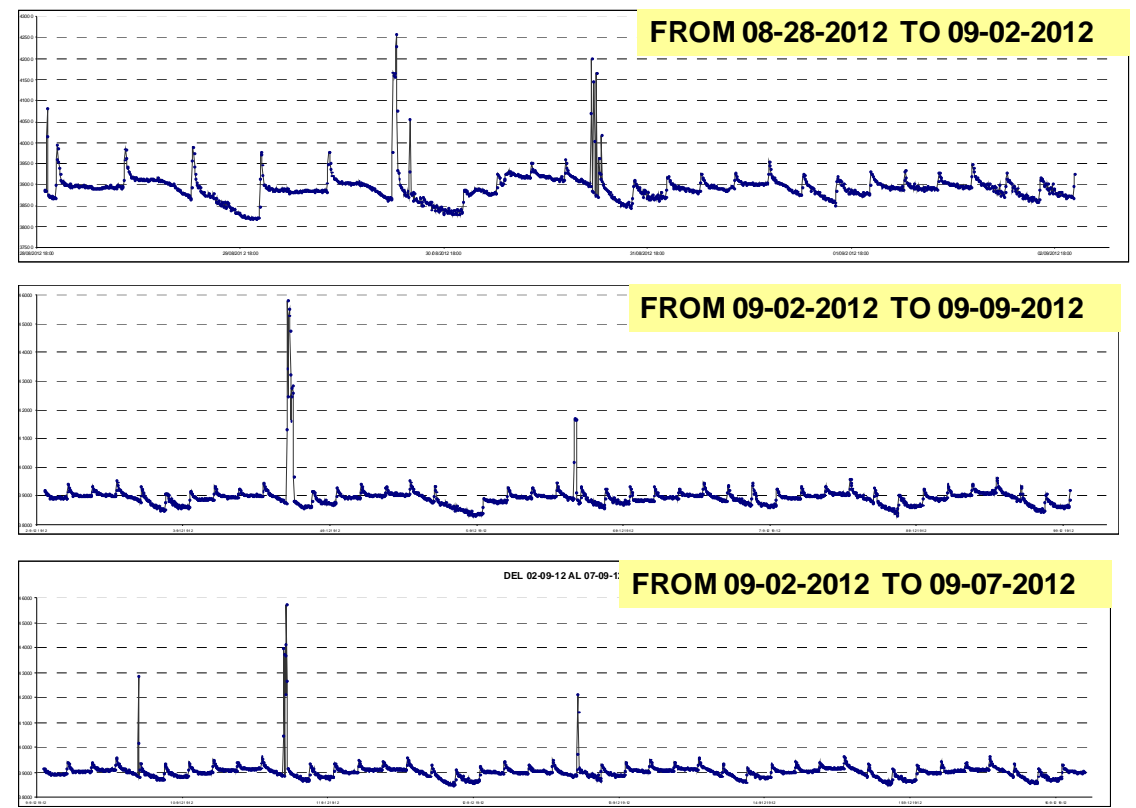

Figure 4: Weekly experimental data during the first 3 weeks of the experiment. Ordinates: weight registered by the lysimeter. Abscises: dates of the experiment. 
In Table 3, the results of the statistical comparison for every methodology of moving average are shown. Weighted moving average is the adequate methodology for data treatment.

Table 3: Comparison among three methodologies of moving average for weekly experimental data.

\begin{tabular}{|c|c|c|c|}
\hline Methodology & MEE (gr) & RMSE (gr) & RE (\%) \\
\hline Simple moving average & -220 & 1115 & 18 \\
\hline $\begin{array}{c}\text { Cumulative moving } \\
\text { average }\end{array}$ & 230 & 995 & 21 \\
\hline $\begin{array}{c}\text { Weighted moving } \\
\text { average }\end{array}$ & 150 & 575 & 5 \\
\hline
\end{tabular}

\section{Conclusions}

Some of the data obtained for a water balance experiment of a grapevine in pot (Vitis Vinifera L. cv Bobal in 110-R) by weighing lysimeter under drip irrigation are presented.

The adequate treatment of data has been the weighted moving average.

Because of the quantity of data in this experiment is necessary to consider the automation of irrigation scheduling in order to apply the specific irrigation dose. The methodology developed could be applied to improve irrigation scheduling in vineyards.

From a similar point of view of data treatment, it is possible to adapt some irrigation practices (deficit irrigation, partial root drying, etc.) to the specific local conditions of the vineyard and use the strictly necessary quantity of water.

This is one of the main objectives for water resource management in an arid zone with water scarcity.

\section{References}

[1] Trambouze, W. and Voltz, M. Measurement and modelling of the transpiration of a Mediterranean vineyard. Agricultural and Forest Meteorology, 107, 153-166, 2001.

[2] Holland, S.E., Below-Canopy Water and Energy Transfer in a North Carolina Vineyard. Faculty of North Carolina State University (Department of Soil Science). 2012.

[3] López-Urrea, R., Montoro, A., Mañas, F., López-Fuster, P. and Fereres, E. Evapotranspiration and crop coefficients from lysimeter measurements of mature 'Tempranillo' wine grapes. Agricultural Water Management, 112, 13-20, 2012.

[4] Centinari, M., Poni, S., Filippetti, I., Magnanini, E. and Intrieri, C. Evaluation of an open portable chamber system for measuring cover crop water use in a vineyard and comparison with a mini-lysimeter approach. Agricultural and Forest Meteorology, 149, 1975-1982, 2009. 
[5] Johnson, R.S., Williams, L.E., Ayars, J.E. and Trout, T.J., Weighing lysimeters aid study of water relations in tree and vine crops. California Agriculture, 59, 133-136, 2005.

[6] Williams, L.E., Irrigation of winegrapes in California. Practical winery and vineyard journal, 2001.

[7] Zhang, B., Kang, S., Zhang, L., Tong, L., Du, T., Li, F. and Zhang, J., An evaporation model for sparsely vegetated canopies under partial root-zone irrigation. Agricultural and Forest Meteorology 149, 2007-2011, 2009

[8] Trambouze, W., Bertuzzi, P. and Voltz, M., Comparison of methods for estimating actual evapotranspiration in a row-cropped vineyard. Agricultural and Forest Meteorology, 91, 193-208, 1998.

[9] Faures, J.M., Goodrich, D.C., Woolhiser, D.A. and Sorooshian, S., Impact of small-scale rainfall variability on runoff model. Journal of hydrology. Amsterdam: Elsevier Science. B.V, 1995.

[10] Kerkides, P., Michalopoulou, H., Papaioannou, G. and Pollatou, R., Water balance estimates over Greece. Agricultural Water Management, 32, 85104, 1996.

[11] Moreno, F., Cayuelas, J.A., Fernández, J.E., Boy, E., Murillo, J.M. and Cabrera, F., Water balance and nitrate leaching in an irrigated maize crop in SW Spain. Agricultural Water Management, 32, 71-83, 1996.

[12] Sánchez-Cohen, I., Lopes, V.L., Slack, D.C. and Fogel, M.M., Water balance model for small scale water harvesting systems. Journal of Irrigation and Drainage Engineering, 132 (2), 123-128, 1997. 